OPEN ACCESS

Edited by:

Lin Zhang,

Ningbo University, China

Reviewed by:

Xueming Lu,

Northeast Normal University, China

Xia Liu,

Beijing Normal University, China

*Correspondence:

Bao Zhao

zhaobao@sdnu.edu.cn

Wenxin Zhang

zhangwenxin@sdnu.edu.cn

Specialty section:

This article was submitted to Evolutionary Psychology,

a section of the journal

Frontiers in Psychology

Received: 30 October 2019

Accepted: 09 January 2020

Published: 18 February 2020

Citation:

Zhao $B$, Cao $Y$, Zhang $L$ and Zhang W (2020) Parenting Practices and Adolescent Effortful Control: MAOA T941G Gene Polymorphism as a Moderator. Front. Psychol. 11:60. doi: 10.3389/fpsyg.2020.00060

\section{Parenting Practices and Adolescent Effortful Control: MAOA T941G Gene Polymorphism as a Moderator}

\author{
Bao Zhao*, Yanmiao Cao, Liang Zhang and Wenxin Zhang* \\ Department of Psychology, Shandong Normal University, Jinan, China
}

Effortful control (EC) plays a crucial role in psychopathology disorders. Emerging studies have paid attention to the effects of $G \times E$ interaction on EC. The present study investigated interactions between monoamine oxidase A (MAOA) T941G polymorphism with parenting practices on EC in a sample of 1,531 Chinese adolescents. The adolescents completed the Early Adolescent Temperament Questionnaire-Revised (EATQ-R) EC scale and the Parenting Style Index provided during the study to assess $\mathrm{EC}$ and parenting practices, respectively. MAOA T941G polymorphism exerted no effect on adolescent EC; however, results revealed that the MAOA gene interacted with parental acceptance/involvement in their associations with EC among boys. Specifically, although increased levels of parental acceptance/involvement benefited all adolescents, boys with $\mathrm{G}$ alleles of the MAOA gene exhibited higher sensitivity to parental acceptance/involvement, compared with $T$ carriers; this interaction was not significant among girls. This study is the first to identify $M A O A \times$ parenting interaction on adolescent $\mathrm{EC}$, further contributing to the literature in MAOA gene-EC.

Keywords: effortful control, monoamine oxidase A, parenting practices, gene-environment interaction, adolescent

\section{INTRODUCTION}

Effortful control, the self-regulatory aspect of temperament, is defined as the ability to inhibit a dominant response to perform a subdominant response, detect errors, and engage in planning (Ellis and Rothbart, 2001; Eisenberger et al., 2005; Rothbart and Bates, 2006). This ability is associated with emotional and behavioral regulation and includes effortful modulation of attention (focusing and directing attention), inhibition control (suppressing dominant responses), and activation control (performing an action when intrinsic motivation is lacking) (Rothbart and Posner, 2005). EC plays a crucial role in the development of psychopathology, particularly externalizing (Doan et al., 2012) and internalizing problems (Rothbart et al., 2003). Deficits in EC can have severe consequences; thus, its antecedents need to be examined.

Abbreviations: EC, effortful control; $M A O A$, monoamine oxidase A. 
Effortful control, an aspect of temperament, is associated with genetic heritability (Gagne et al., 2011) and is a relatively stable, upstream aspect of human behavior. However, evidence also indicates that temperamental experience and expression are shaped by context and experience (Rothbart and Bates, 2006). As a key aspect of such experience in childhood, parenting has been proved to play an important role in the development of EC (Kiff et al., 2011; Stacey et al., 2016). A large literature showed that the robust, replicated findings of beneficial effects of positive environments for EC draw from parenting (Karreman et al., 2006). Compared with children exposed to less maternal empathic, accepting, and supportive parenting behaviors, those who received more positive parenting exhibited better selfregulation (Eisenberg et al., 1998, 2010). Maternal responsiveness has also been associated with self-regulation in adolescents (Doan et al., 2012). Thus, positive parental behaviors exhibit potential as a promotive factor for EC development.

Emerging studies have examined the genetic factors underlying EC, next to environmental factors. Evidence from twin studies has estimated the heritability of EC to reach 79\% (Lemery-Chalfant et al., 2008). Neural and neurochemical studies have suggested that genes implicated in monoamine function are important candidate genes for EC. For instance, dopamine regulates activity in the prefrontal cortex and has been linked to self-control in animal studies (Rodriguiz et al., 2004). Animal and human studies have found that serotonin underlies behavioral inhibition. Serotonin has also been associated with neural regions belonging to the executive attention network involved in self-regulation (Posner et al., 2007). Matrenza et al. (2004) have indicated that experimental depletion of serotonin and catecholamines impair sustained attention, a primary component of EC. Thus, genetic variants implicated in monoamine (e.g., dopamine and serotonin) function are potential genes for EC.

The MAOA gene has been proposed as an important candidate gene for EC because it contributes to the catabolism of monoamine neurotransmitters, including dopamine, serotonin, and norepinephrine (Shih et al., 1999). The MAOA gene is located on the X chromosome at Xp.11.3-Xp11.4. Most studies on the MAOA gene have thus far focused on the variable number tandem repeat (VNTR) in the upstream promoter region of the MAOA gene (Sabol et al., 1998; Buckholtz and Meyer-Lindenberg, 2008; Enge et al., 2011). However, T941G (rs6323), another important functional polymorphism in exon 8, has been related to high (941G) and low (941T) MAOA enzyme activities, particularly among Asians (Fan et al., 2010). The G-allele of T941G single nucleotide polymorphism is associated with elevated MAOA enzyme activity, which results in increased amine degradation and decreased availability of neurotransmitters, such as serotonin, dopamine, and norepinephrine. By contrast, the T-allele of this polymorphism, which is associated with decreased $M A O A$ enzyme activity, leads to decreased amine degradation (Hotamisligil and Breakefield, 1991).

To our knowledge, no existing studies have examined the direct effects of the MAOA gene on EC; however, findings on conduct disorder or attention deficit hyperactivity disorder
(ADHD), which are related to EC deficits, have remained inconclusive. Some studies have shown that high-activity $M A O A$ alleles are related to ADHD (Domschke et al., 2005; Xu et al., 2007) and impulsive personality traits (Manuck et al., 2000) owing to dopamine deficiency caused by increased activation of the MAOA enzyme (Hwang et al., 2018). However, the aforementioned effect has not been confirmed in other studies. Behavioral studies suggest that low-activity MAOA allele carriers may be at a high risk of conduct disorder (Caspi et al., 2002; Kim-Cohen et al., 2006; Cicchetti et al., 2012). A recent study has shown that adolescents with conduct disorders who carried low-activity $M A O A$ variants exhibited relatively pronounced inactivation of the precuneus during an inhibitory task (Sun et al., 2018). In addition, functional magnetic resonance imaging studies have revealed that inhibitory control is accompanied by reduced neural activation in the anterior cingulate cortex of low-activity allele carriers (Fan et al., 2003; Passamonti et al., 2006; Cerasa et al., 2008; Zohsel et al., 2015) with a reduced anterior cingulate cortex volume (Meyer-Lindenberg et al., 2006). High-activity MAOA allele carriers have also exhibited improved anterior cingulate cortex activation, an ECrelated brain region, while completing the Attention Network Test (Fan et al., 2003). The lack of consistency across studies may be partly attributed to the failure of classical approaches adopted to examine genetic association to incorporate interactive effects with environmental factors (Moffitt et al., 2006). However, different levels of environmental exposure may moderate a genetic disposition such that the genetic effect may only become apparent among individuals exposed to one environment and not among individuals exposed to another. Accordingly, geneenvironment interactions $(G \times E)$, defined as genetic effects that are contingent on environmental effects, or vice versa, can explain why some individuals carrying a vulnerable genotype develop a disorder while others remain unaffected (Manfred et al., 2012).

Despite these significant contributions illuminating that EC and related behaviors have a genetic basis (see Eisenberg et al., 2010) that can interact with the quality of the environment in predicting EC, the nature of such interactions has yet to be determined (e.g., Kochanska et al., 2010). According to the differential susceptibility perspective, the gene moderated associations between environmental influences and developmental outcomes from the position that certain individuals are not just more vulnerable to adversity because of their genetic make-up, but disproportionately responsive to positive and negative environmental experiences and exposures (Buil et al., 2015). However, previous studies guided by the diathesis-stress model have largely focused on negative environments and to a lesser extent on positive environment (Monroe and Simons, 1991; Burmeister et al., 2008). Several studies have shown that when exposed to childhood maltreatment, individuals possessing the low-activity $M A O A$ allele may confer an increased risk of conduct disorder (Caspi et al., 2002; Kim-Cohen et al., 2006; Cicchetti et al., 2012). Denson et al. (2014) found low-activity allele carriers to exhibit increased dorsal anterior cingulate cortex and amygdala activation underlying anger control after being insulted. However, some studies (Sjöberg et al., 2007; Åslund et al., 2011) have reported 
that $M A O A$ high-activity alleles confer vulnerability to stress (Widom and Brzustowicz, 2006), whereas MAOA low-activity variants are protective. For instance, low-activity $M A O A$ genotypes have been associated with decreased mood problems, lowered severity of depression, and reduced symptoms of alcohol abuse in victims of sexual abuse (Nikulina et al., 2012). To our knowledge, most studies on gene-environment interactions have focused on negative environmental effects, such as maltreatment and sex abuse. That is, these studies did not look explicitly for the bright side of differential susceptibility. Therefore, this study was aimed to address this gap by exploring the potential interactions between $M A O A$ gene and positive parenting rather than negative environments.

A possible reason for the inconsistency may be that the association between $\mathrm{G} \times \mathrm{E}$ and $\mathrm{EC}$ is moderated by gender. Previous evidence has suggested that $M A O A$-environment interactions on males and females can differ from each other. Several studies have reported that MAOA polymorphism moderates the association between the environment and ECrelated behaviors among adolescent boys, including conduct disorder (Sun et al., 2018), delinquency (Foley et al., 2004), and aggression (Caspi et al., 2002; Wang et al., 2018). However, the interaction of MAOA with psychosocial risk has been found to affect the delinquent behavior of females (Sjöberg et al., 2007). Notably, research has also revealed opposite-direction interactions between $M A O A-\mathrm{VNTR}$ and maltreatment among boys and girls, suggesting that when experiencing maltreatment, boys with the short MAOA-VNTR genotype and girls with long $M A O A-V N T R$ polymorphism conferred increased risks for delinquency (Åslund et al., 2011). Conversely, other studies identified no significant interactions between maltreatment and MAOA-VNTR in boys (Young et al., 2006; Prichard et al., 2008). These results indicated that gene-environment interactions may exert discrepant effects depending on sex. Thus, the present study investigated the potential gender differences in $\mathrm{G} \times \mathrm{E}$ as well.

In summary, although several studies have evaluated the $\mathrm{G} \times \mathrm{E}$ interaction effects on EC and related behaviors, no study has detected an interaction between the MAOA gene and parenting environment. Owing to insufficient relevant evidence, we did not propose a specific hypothesis on the specific allele that confers sensitivity to the environment. The current research aimed to study a large sample of adolescents to explore how MAOA T941G polymorphism interacts with parenting practices in predicting EC in adolescents and whether the effect of this interaction on boys and girls differ from each other.

\section{MATERIALS AND METHODS}

\section{Participants}

Participants consisted of 1,531 Chinese students in Grade 8 (46.5\% girls) recruited from 11 public middle schools in Jinan, Shandong Province, Eastern China. The mean age of the participants was 13.76 years (range: 12-15 years). Most of the participants (86.3\%) were adolescents without siblings. The parents of most adolescents had earned a college/university education or higher (71.1\% of fathers; $61.2 \%$ of mothers). The remaining parents had either a high school education (19.8\% of fathers; $25.6 \%$ of mothers) or a middle school education or less (9.1\% of fathers; $13.2 \%$ of mothers). The respective occupational prestige of mothers and fathers was as follows: $12.0 \%$ of mothers and $5.5 \%$ of fathers were peasants or unemployed, $22.9 \%$ of mothers and $24.1 \%$ of fathers held blue-collar positions, and $65.1 \%$ of mothers and $70.4 \%$ of fathers engaged in professional or semiprofessional occupations. Given indeterminate expression for heterozygous females, they were excluded from analyses $(N=333)$ (Pickles et al., 2013; Zhang et al., 2016).

\section{Procedures}

Participants were asked to collect saliva samples using the Oragene DNA self-collection kit in accordance with the instructions provided by the manufacturer and as instructed in detail by trained researchers in their classroom. We obtained approval from the local ethics committee; in addition, informed assent and consent to participate in the study were obtained from the adolescents and their parents. The participants completed self-reported temperament and parenting style surveys during class hours or immediately after school. Research assistants were present to address the questions of the participants as needed and to ensure confidential and independent responses.

\section{Measurements Effortful Control}

The participants completed a self-reported version of the short form of the Early Adolescent Temperament QuestionnaireRevised (EATQ-R) EC scale, consisting of 16 items (Capaldi and Rothbart, 1992; Ellis and Rothbart, 2001). The activation control dimension includes five items assessing the ability of the respondents to perform an action when a strong tendency to avoid it exists. The attention dimension includes six items assessing the capacity to focus and shift attention when desired. The inhibitory control dimension includes five items assessing the capacity to plan and suppress inappropriate responses. Items were rated on a 5-point scale ranging from 1 (almost always untrue) to 5 (almost always true), with higher scores demonstrating higher EC. The measure exhibited adequate internal consistency $(\alpha=0.81)$. We conduct confirmatory factor analysis (CFA) in software Mplus (Muthén and Muthén, 2012) to evaluate the internal structure of the instrument, applying full information maximum likelihood estimation to address missing data. The factor variance was set to 1 for all models to allow for estimation of item loadings (rather than setting an item loading to 1); item loadings were standardized with respect to latent variable variance (i.e., STD standardized). Preliminary CFA was run to verify the acceptability of EC measurements; the model fit statistics were as follows: CFI $=0.90$, RMSEA $=0.08$, and TLI $=0.90$ (Hu and Bentler, 1999).

\section{Parenting Practices}

The Parenting Style Index (Steinberg et al., 1992) was completed by the participants. The measure included three subscales of acceptance/involvement, psychological autonomy granting, and strictness/supervision. The acceptance/involvement subscale assesses the extent to which an adolescent perceives his/her 
parents as loving, responsive, and involved (nine items, $\alpha=0.86)$. The psychological autonomy granting subscale measures the extent to which parents apply non-coercive, democratic discipline and encourage an adolescent to express individuality within family settings (nine items, $\alpha=0.65$ ). The strictness/supervision subscale measures parental monitoring and adolescent supervision (eight items, $\alpha=0.72$ ). Some items are scored on a 7-point scale while others are on a 3- or 4-point scale. The $z$-score of items was calculated to obtain the mean score of each dimension. Typological and dimensional approaches to parenting style have been applied in previous research (Steinberg et al., 1992, 1994). With the goal of our study considered, specific parenting practices or dimensions (e.g., acceptance or strictness) were measured to obtain a perspective on the overall parenting environment (Darling and Steinberg, 1993).

\section{Genotyping}

DNA was extracted from saliva by using the Oragene DNA self-collection kit (Genotech Inc, Kanata, ON, Canada). Genotyping of MAOA T941G polymorphism was conducted with matrix-assisted laser desorption ionization time-offlight mass spectrometry by using the primers $M A O A-\mathrm{F}$ 5'ACGTTGGATGTGCACTTAAATGACAGTCCC-3' and $M A$ OA-R 5'-ACGTTGGATGGATTCACTTCAGACCAGAGC-3'.

\section{Data Analyses}

All analyses were performed using SPSS Version 16.0 (SPSS Inc., Chicago, IL, United States). Separate analyses were performed for boys and girls because of the X-chromosomal location of the MAOA gene. As previously indicated, 333 heterozygous females were excluded from analysis. In this study, a genotype was dummy-coded into $0=\mathrm{T}$ allele (i.e., $\mathrm{T}$ in boys and $\mathrm{TT}$ in girls) versus $1=\mathrm{G}$ allele (i.e., $\mathrm{G}$ in boys and $\mathrm{GG}$ in girls).

In accordance with the purpose of this study, hierarchical regression analyses were conducted to evaluate the effects of T941G polymorphism, parenting practices, and the interaction of gene and parenting practices on EC. To screen for multicollinearity between independent variables and their interactions in the regression model, the orthogonalized method (Burrill, 2003) using standard regression procedures was applied to boys and girls. Significant gene-environment interactions were further investigated using simple slope analyses. In order to exploring gene-environment interactions, we conducted regression models separated by parenting practices and sex. That is, we conducted six regression analyses. It can be possible to conduct many, separate tests, and the probability of committing a Type I error (i.e., concluding the effect exists even when it does not) for any single test of regression analysis is quite high (Sidak, 1967). Because the significance tests for different operationalization processes of the interaction effect involve numerous non-independent tests; it can be complicated to estimate the exact overall Type I error rate across multiple comparisons (see Benjamini and Yekutieli, 2001). Therefore, to test the robustness of our results, the $p$-values were corrected to control for Type I error by using the Benjamini and Hochberg (1995) procedure.

\section{RESULTS}

The results showed that of the 819 boys, 482 (58.9\%) were G homozygotes, and 337 (41.1\%) were T homozygotes; of the 712 girls, $266(37.3 \%)$ were G/G homozygotes, 333 (46.8\%) were G/T heterozygotes, and 113 (15.9\%) were T/T homozygotes. Genotypic frequencies were consistent with the Hardy-Weinberg equilibrium $\left(\chi^{2}=0.35, d f=1, p>0.05\right)$. Table 1 presents the correlation between variables. All parenting practices showed significant positive correlation with EC; however, MAOA T941G polymorphism was not associated with EC in adolescents. In addition, according to the $t$-test results, higher levels of EC were reported in girls than in boys $\left(t_{(1027)}=-2.29, p=0.02\right)$. Correlation test was conducted to identify any potential geneenvironment correlation ( $r \mathrm{GE}$ ), which implied the association between genotype and parenting practices. An association between genotype and acceptance/involvement was found in boys; specifically, those with $G$ alleles were likely to receive more acceptance/involvement from their parents. In the case of a significant $r \mathrm{GE}$, we performed linear regression with the genotype predicting parenting practices and saved the residuals for inclusion in the follow-up $(G \times E)$ analyses. We then conducted hierarchical regression analyses with the main effects of genotype and parenting practices (acceptance/involvement, psychological autonomy granting, and strictness/supervision) or the residual, in the case of $r \mathrm{GE}$ - in the first step and two-way interaction terms between parenting practices (or residual) and genotype in the second step (Nederhof et al., 2012).

As shown in Table 2, all parenting practices positively predicted EC (boys: acceptance/involvement: $b=0.24$, $p<0.001$; psychological autonomy granting: $b=0.21$, $p<0.001$; strictness/supervision: $b=0.09, p<0.001$; girls: acceptance/involvement: $b=0.20, p<0.001$; psychological autonomy granting: $b=0.12, p<0.001$; strictness/supervision: $b=0.07, p<0.05)$. No significant main effect of MAOA T941G genotype on EC was observed among male and female adolescents. However, a two-way interaction between the MAOA T941G genotype and parental acceptance/involvement in the association with EC was found among boys (corrected $p=0.048$ ) but not among girls (corrected $p=0.25$ ). An interaction between T941G polymorphism and strictness/supervision was not present in boys (corrected $p=1.02$ ) or girls (corrected $p=0.053$ ). Moreover, no significant interaction effects of MAOA T941G and psychological autonomy granting were found in boys (corrected $p=0.63$ ) or girls (corrected $p=0.58$ ).

To interpret the interaction effect between $M A O A$ and acceptance/involvement, a follow-up simple slope analysis was conducted. Results indicated that among all boys, increased parental acceptance/involvement significantly predicted higher EC in $\mathrm{G}$ allele carriers $(b=0.37, t=10.72, p<0.001)$ and $\mathrm{T}$ allele carriers $(b=0.26, t=6.69, p<0.001)$; however, the interaction effects between parenting practice and two genotype carriers were significantly different from each other. In low parental acceptance, $G$ allele carriers demonstrated lower EC than T carriers (Figure 1). Compared with $\mathrm{T}$ carriers, $\mathrm{G}$ allele carriers performed better on EC when exposed to higher parental acceptance/involvement. These 
TABLE 1 | Descriptive statistics and correlations among study variables.

\begin{tabular}{|c|c|c|c|c|c|c|}
\hline Variables & Effortful control & MAOA T941G & SES & Acceptance/involvement & $\begin{array}{l}\text { Psychological } \\
\text { autonomy-granting }\end{array}$ & Strictness/supervision \\
\hline Effortful control & - & 0.00 & $0.12^{*}$ & $0.39^{\star \star}$ & $0.24^{* *}$ & $0.15^{\star \star}$ \\
\hline MAOA T941G & 0.06 & - & -0.04 & -0.01 & -0.10 & 0.02 \\
\hline SES & $0.14^{\star *}$ & 0.03 & - & 0.09 & 0.10 & $0.16^{\star \star}$ \\
\hline Acceptance/involvement & $0.44^{\star *}$ & $0.10^{\star \star}$ & $0.14^{\star \star}$ & - & $0.35^{\star \star}$ & $0.21^{\star \star}$ \\
\hline Psychological autonomy-granting & $0.42^{\star *}$ & 0.01 & $0.15^{\star \star}$ & $0.14^{\star \star}$ & - & -0.05 \\
\hline Strictness/supervision & $0.18^{\star *}$ & 0.05 & 0.04 & $0.15^{\star \star}$ & 0.05 & - \\
\hline Mean(SD) (Boys) & $3.75(0.53)$ & & $-0.01(0.79)$ & 3.22 (0.55) & $2.75(0.45)$ & $2.96(0.52)$ \\
\hline Mean(SD) (Girls) & $3.83(0.52)$ & & $0.01(0.76)$ & $3.30(0.48)$ & $2.87(0.44)$ & $3.23(0.44)$ \\
\hline
\end{tabular}

Numbers above the diagonal refer to girls, and numbers below the diagonal refer to boys. ${ }^{*} p<0.05,{ }^{* *} p<0.01$.

TABLE 2 | Hierarchical linear regression analysis of the associations among MAOA T941G, parenting practices, and effortful control.

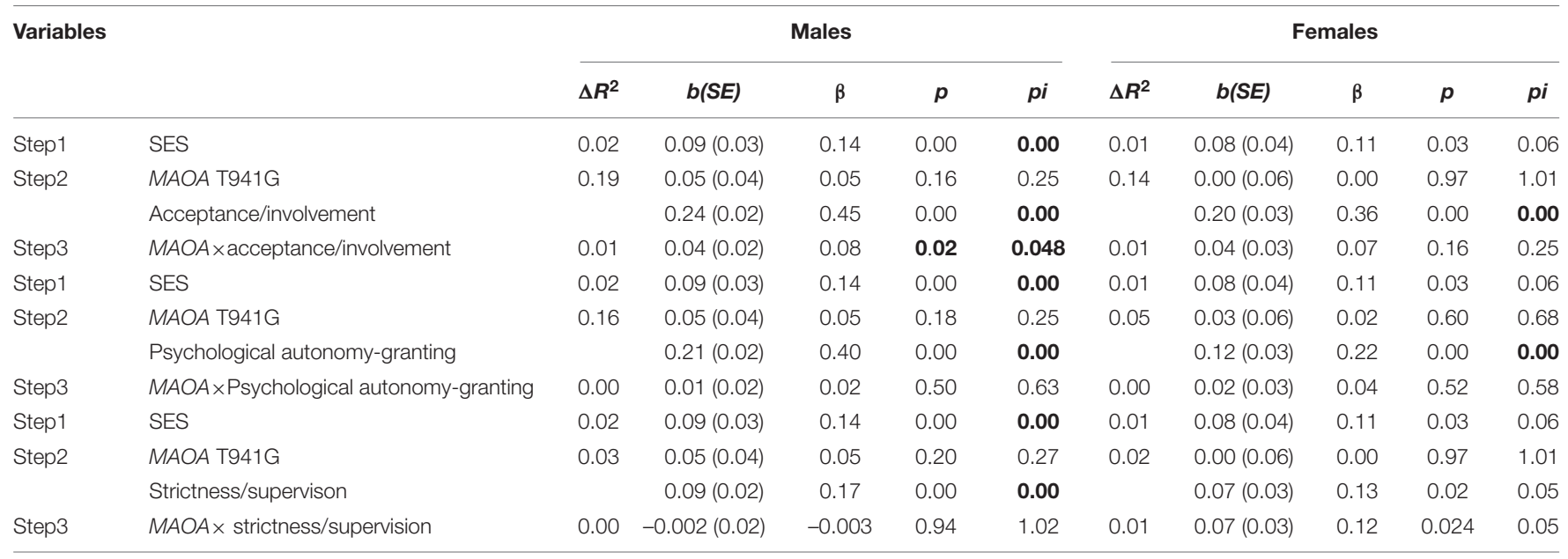

pi refers to corrected p-values. Significant results after $B$ - $H$ correction are in bold.

statistical indices indicate that the $G$ allele is the more sensitive genotype.

\section{DISCUSSION}

The present study aimed to explore the interaction effects of MAOA T941G polymorphism and parenting practices on EC in a large community sample of Chinese adolescents. Our study provided initial evidence for the potential interaction of the MAOA gene and parenting on EC in adolescents, and no significant main effect of MAOA T941G polymorphism on EC was found. When exposed to low parental acceptance/involvement, the adolescents with $\mathrm{G}$ alleles exhibited lower EC than those who with $\mathrm{T}$ alleles. This finding remained robust after corrections.

The results showed that higher levels of parental acceptance/involvement, psychological autonomy granting, and strictness/supervision promoted higher EC in adolescents. These findings provide additional evidence of the importance of parenting in the development of EC in adolescents, consistent with prior studies (Stacey et al., 2016; Huang et al., 2017). In contrast to parenting, MAOA T941G polymorphism exerted no main effect. This result further suggested that the link between

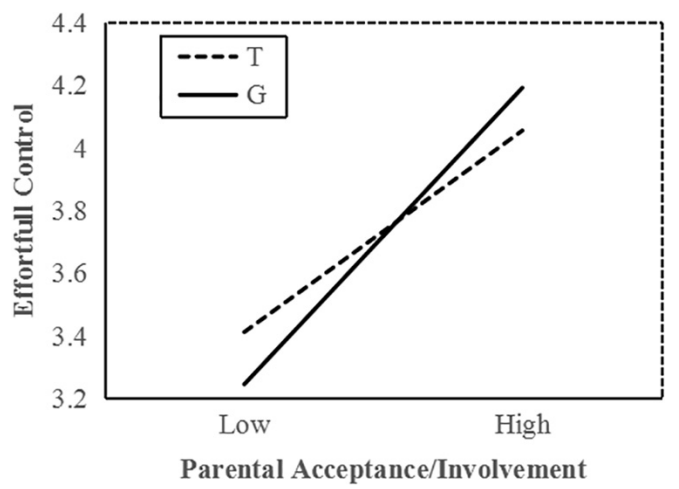

FIGURE 1 | MAOA T941G and parental acceptance/involvement in predicting EC in boys. Simple slopes predict EC from parenting practices in different genotype groups. Solid line, G allele; dashed line, T allele.

a single gene and complex behavior is often too weak to be identified (Durston et al., 2005).

Notably, the results also indicated that MAOA T941G moderated the effect of parental acceptance/involvement on EC. Specifically, compared with the adolescents carrying $\mathrm{T}$ alleles, 
those carrying $G$ alleles exhibited higher sensitivity to parental acceptance/involvement in predicting EC. Similarly, Larson et al. (2010) found that individuals with GG genotypes exhibited sustained eye movement to unpleasant emotional pictures (i.e., delayed recovery following negative affective stimuli), in contrast to those carrying TT genotypes. The current study suggested that the $\mathrm{G}$ allele was more easily affected by environment than $\mathrm{T}$ allele. Accordingly, we speculate that the adolescents with G genotype may be more likely to capture various emotions and information in environments (in this case, parental acceptance/involvement) by evoking emotion-related brain regions and neurophysiological over activation. By contrast, the MAOA T allele was presumed to be associated with less activation in the prefrontal regions, particularly the anterior cingulate cortex (Fan et al., 2003; MeyerLindenberg et al., 2006; Passamonti et al., 2006) and dorsal anterior cingulate cortex (Sun et al., 2018). The low activation of these brain regions may further reduce the possibility of capturing different information from the parenting environment. Therefore, these findings suggested that $G$ alleles were the susceptible alleles, and the adolescents with $G$ alleles were more sensitive to parental acceptance/involvement, compared with those carrying $\mathrm{T}$ alleles.

Another possible underlying mechanism to which $\mathrm{G} \times \mathrm{E}$ interaction can be attributed is that exposure to different environments alters the genetic vulnerability of adolescents by influencing the expression of a genetic factor (Johnson, 2007). That is, some genetic factors may block or suppress the influence of the environmental exposure of adolescents, leading to reduced sensitivity to different environmental effects (SonugaBarke et al., 2009; Sun et al., 2018). In the present study, MAOA $\mathrm{T}$ polymorphism (associated with lower monoamine oxidase function) served as a genetic factor that weakened the impact of parenting environment (in this case, parental acceptance/involvement). Such adolescents may benefit less from increased parental involvement/acceptance than G-carriers and be capable of buffering the negative effect of decreased parental involvement/acceptance, exhibiting resilient behaviors (in our study, relatively similar EC).

In this study, the $G \times E$ interaction manifested in boys but not in girls. The reason for gender differences in the interaction has yet to be determined. Gender-specific effects may be attributed to sex differences in hormonal factors that influence gene expression. Sjöberg et al. (2008) found a non-additive interaction between the MAOA gene and testosterone in predicting impulsive behavior, which is linked to EC. During puberty, males experience a rapid increase in testosterone, which may further alter geneenvironment interactions. Moreover, the heterozygous girls were excluded from analyses given unknown patterns of $\mathrm{X}$-inactivation in girls. Regardless, Carrel and Willard (2005) suggested that $M A O A$ can evade $\mathrm{X}$-inactivation. In the case of MAOA partly escaping X-inactivation, the effect of $M A O A$ polymorphism on the female phenotype is more difficult to predict and may also result in non-significant $G \times E$ interaction. Therefore, explanations for gender differences in genetic susceptibility to EC remain an important direction for future research.
To the best of our knowledge, our findings provide initial evidence for the potential effects of the MAOA gene and parenting on EC in adolescents. Moreover, investigation of a large, community-based adolescent sample can increase the generalizability of findings. This study included participants of both sexes and identified different results of the $M A O A \times$ parenting interaction. Moreover, we focused on the $\mathrm{G} \times \mathrm{E}$ interaction in adolescence, which is a critical period for the development of EC with less attention. We also performed a Benjamini and Hochberg (1995) correction procedure to minimize the false discovery rate.

Despite these strengths, several limitations should be considered. Notably, the confounding introduced by $r \mathrm{GE}$ may reduce the reliability of the $\mathrm{G} \times \mathrm{E}$ interaction observed in this study. Although we sought to control for $r \mathrm{GE}$ by using statistical methods, these findings should be interpreted with caution until replicated. Second, in the current study, single informants were used to assess EC and parenting; multiple informants should be involved in subsequent research. With such a large sample, accessing EC and parenting via observational measures would be infeasible. In addition, self-report questionnaires comprise one of the most common and effective ways to assess parenting among adolescents (Chen et al., 2000; Zhang et al., 2015). Third, the current study was cross-sectional; thus, care should be taken in inferring causality between parenting and adolescent EC. Finally, given that $M A O A$ polymorphism plays an important regulatory role between parenting and EC in adolescents, further consideration of the interaction including multiple genes warrants exploration.

\section{CONCLUSION}

The present study provides initial evidence of the effect of the MAOA T941G $\times$ parenting practices interaction on EC in adolescents, emphasizing the value of testing the $\mathrm{G} \times \mathrm{E}$ interaction on EC and elucidating the effect of the MAOA gene on EC. These results also provide new insights into the interaction of genetic susceptibility with parenting in predicting EC. Our findings revealed that the $G$ allele acts as a more susceptible factor that affords sensitivity to adolescents in parenting environments. Although further research is needed to replicate this effect and explore the potential mechanism underlying this genetic susceptibility, our study indicates that the MAOA T941G polymorphism $\times$ parenting practices interaction is beneficial for EC in adolescents. Our study also presents further evidence of the important effects of monoamines on EC in adolescents, contributing to the literature on the effect of the $M A O A$ gene on EC.

\section{DATA AVAILABILITY STATEMENT}

The datasets for this manuscript are not publicly available due to data confidentiality. Requests to access the datasets should be directed to WZ, zhangwenxin@sdnu.edu.cn. 


\section{ETHICS STATEMENT}

The studies involving human participants were reviewed and approved by the Ethics Committee of Shandong Normal University. Written informed consent to participate in this study was provided by the participants' legal guardian/next of kin.

\section{AUTHOR CONTRIBUTIONS}

$\mathrm{BZ}, \mathrm{YC}$, and $\mathrm{WZ}$ contributed to the conception and design of the study. BZ conducted the analysis and drafted the manuscript. YC helped in performing the statistical analysis and drafting the manuscript. LZ helped in conducting the statistical analysis. WZ conceived and coordinated the study and helped to draft

\section{REFERENCES}

Åslund, C., Nordquist, N., Comasco, E., Leppert, J., Oreland, L., and Nilsson, K. W. (2011). Maltreatment, MAOA, and delinquency: sex differences in geneenvironment interaction in a large population-based cohort of adolescents. Behav. Genet. 41, 262-272. doi: 10.1007/s10519-010-9356-y

Benjamini, Y., and Hochberg, Y. (1995). Controlling the false discovery rate: a practical and powerful approach to multiple testing. R. Stat. Soc. B. 57, 289-300. doi: 10.1111/j.2517-6161.1995.tb02031.x

Benjamini, Y., and Yekutieli, D. (2001). The control of the false discovery rate in multiple testing under dependency. Ann. Stat. 29, 1165-1188. doi: 10.1186/ 1471-2105-9-114

Buckholtz, J. W., and Meyer-Lindenberg, A. (2008). MAOA and the neurogenetic architecture of human aggression. Trends Neurosci. 31, 120-129. doi: 10.1016/j. tins.2007.12.006

Buil, A., Brown, A. A., Lappalainen, T., Viñuela, A., Davies, M. N., Zheng, H. F., et al. (2015). Gene-gene and gene-environment interactions detected by transcriptome sequence analysis in twins. Nat. Genet. 47, 88-91. doi: 10.1038/ ng. 3162

Burmeister, M., Mcinnis, M. G., and Sebastian, Z. L. (2008). Psychiatric genetics: progress amid controversy. Nat. Rev. Genet. 9, 527-540. doi: 10.1038/nrg 2381

Burrill, D. F. (2003). Modeling and Interpreting Interactions in Multiple Regression. Available at: http://www.minitab.com/resources/whitepapers/burril2.htm [accessed February 27, 2003].

Capaldi, D. M., and Rothbart, M. K. (1992). Development and validation of an early adolescent temperament measure. J. Early Adolesc. 12, 153-173. doi: $10.1177 / 0272431692012002002$

Carrel, L., and Willard, H. F. (2005). X-inactivation profile reveals extensive variability in X-linked gene expression in females. Nature 434, 400-404. doi: 10.1038/nature03479

Caspi, A., McClay, J., Moitt, T. E., Mill, J., Martin, J., Craig, I. W., et al. (2002). Role of genotype in the cycle of violence in maltreated children. Science 297, 851-854. doi: 10.1126/science. 1072290

Cerasa, A., Gioia, M. C., Fera, F., Passamonti, L., Liguori, M., Lanza, P., et al. (2008). Ventro-lateral prefrontal activity during working memory is modulated by MAOA genetic variation. Brain Res. 1201, 114-121. doi: 10.1016/j.brainres. 2008.01.048

Chen, X., Liu, M., and Li, D. (2000). Parental warmth, control, and indulgence and their relations to adjustment in Chinese children: a longitudinal study. J. Fam. Psychol. 14, 401-419. doi: 10.1037/0893-3200.14.3.401

Cicchetti, D., Rogosch, F. A., and Thibodeau, E. L. (2012). The effects of child maltreatment on early signs of antisocial behavior: genetic moderation by tryptophan hydroxylase, serotonin transporter, and monoamine oxidase A genes. Dev. Psychopathol. 24, 907-928. doi: 10.1017/\$095457941200 0442

Darling, N., and Steinberg, L. (1993). Parenting style as context: an integrative model. Psychol. Bull. 113, 487-493. doi: 10.1037/0033-2909.113.3.487 the manuscript. All authors approved the final version of the manuscript for submission.

\section{FUNDING}

This research was supported by the National Natural Science Foundation of China (31671156).

\section{ACKNOWLEDGMENTS}

We are grateful to all the adolescents, parents, and research staff who taken part in or contributed to the present study.

Denson, T. F., Dobson-Stone, C., Ronay, R., von Hippel, W., and Schira, M. M. (2014). A functional polymorphism of the MAOA gene is associated with neural responses to induced anger control. J. Cogn. Neurosci. 26, 1418-1427. doi: 10.1162/jocn_a_00592

Doan, S. N., Fuller-Rowell, T. E., and Evans, G. W. (2012). Cumulative risk and adolescent's internalizing and externalizing problems: the mediating roles of maternal responsiveness and self-regulation. Dev. Psychol. 48, 1529-1539. doi: $10.1037 / \mathrm{a} 0027815$

Domschke, K., Sheehan, K., Lowe, N., Kirley, A., Mullins, C., O’Sullivan, R., et al. (2005). Association analysis of the monoamine oxidase A and B genes with attention deficit hyperactivity disorder (ADHD) in an Irish sample: preferential transmission of the MAO-A 941g allele to affected children. Am. J. Med. Genet. B Neuropsychiatr. Genet. 134B, 110-114. doi: 10.1002/ajmg.b.30158

Durston, S., Fossella, J. A., Casey, B. J., Pol, H. E. H., Galvan, A., Schnack, H. G., et al. (2005). Differential effects of DRD4 and DAT1 genotype on fronto-striatal gray matter volumes in a sample of subjects with attention deficit hyperactivity disorder, their unaffected siblings, and controls. Mol. Psychiatry 10, 678-685. doi: 10.1038/sj.mp.4001649

Eisenberg, N., Cumberland, A., and Spinrad, T. L. (1998). Parental socialization of emotion. Psychol. Inq. 9, 241-273.

Eisenberg, N., Spinrad, T. L., and Eggum, N. D. (2010). Emotion-related selfregulation and its relation to children's maladjustment. Annu. Rev. Clin. Psychol. 6, 495-525. doi: 10.1146/annurev.clinpsy.121208.131208

Eisenberger, N. I., Lieberman, M. D., and Satpute, A. B. (2005). Personality from a controlled processing perspective: an fMRI study of neuroticism, extraversion, and self-consciousness. Cogn. Affect. Behav. Neurosci. 5, 169-181. doi: 10.3758/ cabn.5.2.169

Ellis, L. K., and Rothbart, M. K. (2001). "Revision of the early adolescent temperament questionnaire," in Poster Presented at the 2001 Biennial Meeting of the Society for Research in Child Development (Minneapolis, MN).

Enge, S., Fleischhauer, M., Lesch, K. P., Reif, A., and Strobel, A. (2011). Serotonergic modulation in executive functioning: linking genetic variations to working memory performance. Neuropsychologia 49, 3776-3785. doi: 10.1016/ j.neuropsychologia.2011.09.038

Fan, J., Fossella, J., Sommer, T., Wu, Y., and Posner, M. I. (2003). Mapping the genetic variation of executive attention onto brain activity. Proc. Natl. Acad. Sci. U.S.A. 100, 7406-7411. doi: 10.1073/pnas.0732088100

Fan, M., Liu, B., Jiang, T., Jiang, X., Zhao, H., and Zhang, J. (2010). Meta-analysis of the association between the monoamine oxidase-A gene and mood disorders. Psychiatr. Genet. 20, 1-7. doi: 10.1097/ypg.0b013e3283351112

Foley, D. L., Eaves, L. J., Wormley, B., Silberg, J. L., Maes, H. H., Kuhn, J., et al. (2004). Childhood adversity, monoamine oxidase a genotype, and risk for conduct disorder. Arch. Gen. Psychiatry 61, 738-744.

Gagne, J. R., Saudino, K. J., and Asherson, P. (2011). The genetic etiology of inhibitory control and behavior problems at 24 months of age. J. Child Psychol. Psychiatry 52, 1155-1163. doi: 10.1111/j.1469-7610.2011.02420.x

Hotamisligil, G. S., and Breakefield, X. O. (1991). Human monoamine oxidase A gene determines levels of enzyme activity. Am. J. Hum. Genet. 49, 383-392. 
Hu, L. T., and Bentler, P. M. (1999). Cutoff criteria for fit indexes in covariance structure analysis: conventional criteria versus new alternatives. Struct. Equ. Model. 6, 1-55. doi: 10.1080/10705519909540118

Huang, C. Y., Charissa, S. L. C., Michael, E. L., and Zhou, N. (2017). Associations between parenting styles and perceived child effortful control within Chinese families in the United States, the United Kingdom, and Taiwan. J. Cross Cult. Psychol. 48, 795-812. doi: 10.1177/0022022117706108

Hwang, I., Lim, M., Kwon, H., and Jin, H. (2018). Association of Monoamine oxidase A (MAOA) Gene uVNTR and rs6323 polymorphisms with attention deficit and hyperactivity disorder in Korean Children. Medicina 54:32. doi: 10.3390/medicina54030032

Johnson, W. (2007). Genetic and environmental influences on behavior: capturing all the interplay. Psycholog. Rev. 114, 423-440. doi: 10.1037/0033-295x.114. 2.423

Karreman, A., Van Tuijl, C., Van Aken, M. A. G., and Dekovic, M. (2006). Parenting and self-regulation in preschoolers: a meta-analysis. Infant Child Dev. 15, 561-579. doi: 10.1002/icd.478

Kiff, C. J., Lengua, L. J., and Zalewski, M. (2011). Nature and nurturing: parenting in the context of child temperament. Clin. Child Fam. Psychol. Rev. 14, 251-301. doi: 10.1007/s10567-011-0093-4

Kim-Cohen, J., Caspi, A., Taylor, A., Williams, B., Newcombe, R., Craig, I. W., et al. (2006). MAOA, maltreatment, and gene-environment interaction predicting children's mental health: new evidence and a meta-analysis. Mol. Psychiatry 11, 903-913. doi: 10.1038/sj.mp.4001851

Kochanska, G., Philibert, R. A., and Barry, R. A. (2010). Interplay of genes and early mother-child relationship in the development of self-regulation from toddler to preschool age. J. Child Psychol. Psychiatr. 50, 1331-1338. doi: 10.1111/j.14697610.2008.02050.x

Larson, C. L., Taubitz, L. E., and Robinson, J. S. (2010). MAOA T941G polymorphism and the time course of emotional recovery following unpleasant pictures. Psychophysiology 47, 857-862. doi: 10.1111/j.1469-8986.2010.01 005. $x$

Lemery-Chalfant, K., Doelger, L., and Goldsmith, H. H. (2008). Genetic relations between effortful and attentional control and symptoms of psychopathology in middle childhood. Infant Child Dev. 17, 365-385. doi: 10.1002/icd.581

Manfred, L., Dorothea, B., Arlette, F. B., Jens, T., Martin, H. S., Günter, E., et al. (2012). Catechol-O-methyltransferase Val 158 Met genotype, parenting practices and adolescent alcohol use: testing the differential susceptibility hypothesis. J. Child Psychol. Psychiatry 53, 351-359. doi: 10.1111/j.1469-7610. 2011.02408.x

Manuck, S. B., Flory, J. D., Ferrell, R. E., Mann, J. J., and Muldoon, M. F. (2000). A regulatory polymorphism of the monoamine oxidase-A gene may be associated with variability in aggression, impulsivity, and central nervous system serotonergic responsivity. Psychiatry Res. 95, 9-23. doi: 10.1016/s0165$1781(00) 00162-1$

Matrenza, C., Hughes, J. M., Kemp, A. H., Wesnes, K. A., Harrison, B. J., and Nathan, P. J. (2004). Simultaneous depletion of serotonin and catecholamines impairs sustained attention in healthy female subjects without affecting learning and memory. J. Psychopharmacol. 18, 21-31. doi: 10.1177/0269881104040215

Meyer-Lindenberg, A., Buckholtz, J. W., Kolachana, B., Pezawas, R. H. A., Blasi, L., Wabnitz, G., et al. (2006). Neural mechanisms of genetic risk for impulsivity and violence in humans. Proc. Natl. Acad. Sci. U.S.A. 103, 6269-6274. doi: 10.1073/pnas. 05113

Moffitt, T. E., Caspi, A., and Rutter, M. (2006). Measured gene-environment interactions in psychopathology: concepts, research strategies, and implications for research, intervention, and public understanding of genetics. Perspect Psychol Sci. 1, 5-27. doi: 10.1111/j.1745-6916.2006.00002.x

Monroe, S. M., and Simons, A. D. (1991). Diathesis-stress theories in the context of life stress research: implications for the depressive disorders. Psychol. Bull. 110, 406-425. doi: 10.1037//0033-2909.110.3.406

Muthén, L. K., and Muthén, B. O. (2012). Mplus User's Guide, 7th Edn. Los Angeles, CA: Muthén \& Muthén.

Nederhof, E., Belsky, J., Ormel, J., and Oldehinkel, A. J. (2012). Effects of divorce on Dutch boys' and girls' externalizing behavior in Gene $\times$ environment perspective: diathesis stress or differential susceptibility in the Dutch tracking adolescents' individual lives survey study? Dev. Psychopathol. 24, 929-939. doi: $10.1017 / \mathrm{S} 0954579412000454$
Nikulina, V., Widom, C. S., and Brzustowicz, L. M. (2012). Child abuse and neglect, MAOA, and mental health outcomes: a prospective examination. Biol. Psychiatry 71, 350-357. doi: 10.1016/j.biopsych.2011.09.008

Passamonti, L., Fera, F., Magariello, A., Cerasa, A., Gioia, M. C., Muglia, M., et al. (2006). Monoamine oxidase-a genetic variations influence brain activity associated with inhibitory control: new insight into the neural correlates of impulsivity. Biol. Psychiatry 59, 334-340. doi: 10.1016/j.biopsych.2005.07.027

Pickles, A., Hill, J., Breen, G., Quinn, J., Abbott, K., Jones, H., et al. (2013). Evidence for interplay between genes and parenting on infant temperament in the first year of life: monoamine oxidase A polymorphism moderates effects of maternal sensitivity on infant anger proneness. J. Child Psychol. Psychiatry 54, 1308-1317. doi: $10.1111 /$ jcpp. 12081

Posner, M. I., Rothbart, M. K., and Sheese, B. E. (2007). Attention genes. Dev. Sci. $10,24-29$.

Prichard, Z., Mackinnon, A., Jorm, A. F., and Easteal, S. (2008). No evidence for interaction between MAOA and childhood adversity for antisocial behavior. Am. J. Med. Genet. B 147B, 228-232. doi: 10.1002/ajmg.b.30581

Rodriguiz, R. M., Chu, R., Caron, M. G., and Wetsel, W. C. (2004). Aberrant responses in social interaction of dopamine transporter knockout mice. Behav. Brain Res. 148, 185-198. doi: 10.1016/s0166-4328(03)00187-6

Rothbart, M. K., and Bates, J. E. (2006). "Temperament," in Handbook of Child Psychology: Vol. 3. Social, Emotional, and Personality Development, 6th Edn, eds W. Damon, R. Lerner, and N. Eisenberg (New York, NY: Wiley), 99-166.

Rothbart, M. K., Ellis, L. K., Rueda, M. R., and Posner, M. I. (2003). Developing mechanisms of temperamental effortful control. J. Pers. 71, 1113-1144. doi: 10.1111/1467-6494.7106009

Rothbart, M. K., and Posner, M. I. (2005). Genes and experience in the development of executive attention and effortful control. New Dir. Child Adolesc. Dev. 109, 101-108. doi: 10.1002/cd.142

Sabol, S. Z., Hu, S., and Hamer, D. (1998). A functional polymorphism in the monoamine oxidase a gene promoter. Hum. Genet. 103, 273-279. doi: 10.1007/ s004390050816

Shih, J. C., Chen, K., and Ridd, M. J. (1999). Monoamine oxidase: from genes to behavior. Annu. Rev. Neurosci. 22, 197-217. doi: 10.1146/annurev.neuro.22. 1.197

Sidak, Z. (1967). Rectangular confidence region for the means of multivariate normal distributions. J. Am. Stat. Assoc. 62, 626-633. doi: 10.1080/01621459. 1967.10482935

Sjöberg, R. L., Ducci, F., Barr, C. S., Newman, T. K., Dell'Osso, L., Virkkunen, M., et al. (2008). A non-additive interaction of a functional MAO-A VNTR and testosterone predicts antisocial behavior. Neuropsychopharmacology 33, 425-430. doi: 10.1038/sj.npp.1301417

Sjöberg, R. L., Nilsson, K. W., Wargelius, H. L., Leppert, J., Lindstrom, L., and Oreland, L. (2007). Adolescent girls and criminal activity: role of MAOA-LPR genotype and psychosocial factors. Am. J. Med. Genet. B Neuropsychiatr. Genet. 144B, 159-164. doi: 10.1002/ajmg.b.30360

Sonuga-Barke, E. J., Oades, R. D., Psychogiou, L., Chen, W., Franke, B., Buitelaar, J. K., et al. (2009). Dopamine and serotonin transporter genotypes moderate sensitivity to maternal expressed emotion: the case of conduct and emotional problems in attention deficit/hyperactivity disorder. J. Child Psychol. Psychiatry 50, 1052-1063. doi: 10.1111/j.1469-7610.2009.02095.x

Stacey, S. T., Deborah, M. C., David, C. R. K., Maria, B., Katherine, C. P., and Lee, O. (2016). Parenting and the development of effortful control from early childhood to early adolescence: a transactional. Dev. Psychopathol. 28, 837-853. doi: 10.1017/S0954579416000341

Steinberg, L., Lamborn, S. D., Darling, N., Mounts, N. S., and Dornbusch, S. M. (1994). Impact of parenting practices on adolescent achievement: authoritative parenting, school involvement, and encouragement to succeed. Child Dev. 65, 754-770.

Steinberg, L., Lamborn, S. D., Dornbusch, S. M., and Darling, N. (1992). Impact of parenting practices on adolescent achievement: authoritative parenting, school involvement, and encouragement to succeed. Child Dev. 63, 1266-1281. doi: 10.1111/j.1467-8624.1992.tb01694.x

Sun, X., Ma, R., Jiang, Y., Gao, Y., Ming, Q., Wu, Q., et al. (2018). MAOA genotype influences neural response during an inhibitory task in adolescents with conduct disorder. Eur. Child Adolesc. Psychiatry 27, 1159-1169. doi: 10. 1007/s00787-018-1170-8 
Wang, M., Li, H., Deater-Deckard, K., and Zhang, W. (2018). Interacting effect of Catechol-O-Methyltransferase (COMT) and Monoamine Oxidase A (MAOA) gene polymorphisms, and stressful life events on aggressive behavior in Chinese male adolescents. Front. Psychol. 9:1079. doi: 10.3389/fpsyg.2018. 01079

Widom, C. S., and Brzustowicz, L. M. (2006). MAOA and the "cycle of violence:" childhood abuse and neglect, MAOA genotype, and risk for violent and antisocial behavior. Biol. Psychiatry 60, 684-689. doi: 10.1016/j.biopsych.2006. 03.039

Xu, X., Brookes, K., Chen, C. K., Huang, Y. S., Wu, Y. Y., and Asherson, P. (2007). Association study between the monoamine oxidase A gene and attention deficit hyperactivity disorder in Taiwanese samples. BMC Psychiatry 7:10. doi: 10.1186/ 1471-244X-7-10

Young, S. E., Smolen, A., Hewitt, J. K., Haberstick, B. C., Stallings, M. C., Corley, R. P., et al. (2006). Interaction between MAO-A genotype and maltreatment in the risk for conduct disorder: failure to confirm in adolescent patients. Am. J. Psychiatry 163, 1019-1025. doi: 10.1176/ajp.2006.163.6. 1019

Zhang, W., Cao, C., Wang, M., Ji, L., and Cao, Y. (2016). Monoamine Oxidase A (MAOA) and Catechol-O-Methyltransferase (COMT) Gene Polymorphisms Interact with Maternal Parenting in Association with Adolescent Reactive Aggression but not Proactive Aggression: Evidence of
Differential Susceptibility. J. Youth Adolesc. 45, 812-829. doi: 10.1007/s10964016-0442-1

Zhang, W., Cao, Y., Wang, M., Ji, L., Chen, L., and Deater-Deckard, K. (2015). The Dopamine D2 Receptor Polymorphism (DRD2 TaqIA) interacts with maternal parenting in predicting early adolescent depressive symptoms: evidence of differential susceptibility and age differences. J. Youth Adolesc. 44, 1428-1440. doi: 10.1007/s10964-015-0297-x

Zohsel, K., Bianchi, V., Mascheretti, S., Hohm, E., Schmidt, M. H., Esser, G., et al. (2015). Monoamine oxidase A polymorphism moderates stability of attention problems and susceptibility to life stress during adolescence. Genes Brain Behav. 14, 565-572. doi: $10.1111 / \mathrm{gbb} .12258$

Conflict of Interest: The authors declare that the research was conducted in the absence of any commercial or financial relationships that could be construed as a potential conflict of interest

Copyright (c) 2020 Zhao, Cao, Zhang and Zhang. This is an open-access article distributed under the terms of the Creative Commons Attribution License (CC BY). The use, distribution or reproduction in other forums is permitted, provided the original author(s) and the copyright owner(s) are credited and that the original publication in this journal is cited, in accordance with accepted academic practice. No use, distribution or reproduction is permitted which does not comply with these terms. 